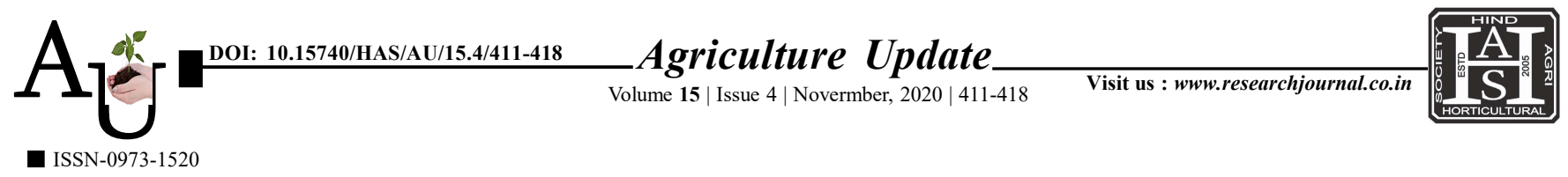

\title{
Research Article: Knowledge and awareness of farmers with respect to climate change on cropping pattern of vegetable crops in Sehore district of Madhya Pradesh
}

Q Vikram Singh and Hansraj Jatav

Article Chronicle : Received :

15.02.2020;

Revised:

05.10.2020;

Accepted :

$24 . .10 .2020$

KEY WoRds :

Knowledge, Awareness, Farmers, Cropping pattern, Climate change sampling method.
SUMMARY : The present study was confined to Sehore district of Madhya Pradesh. Sehore district which is situated in the west part of the Madhya Pradesh lies between latitudes 30 $33^{\prime}$ ' and 23 ${ }^{\circ} 54^{\prime}$ North and longitudes $76^{\circ} 11^{\prime}$ and $78^{\circ} 02^{\prime}$ 'East. It is surrounded by Dewas and Shajapur districts in the west, Rajgarh district in the North-West and Vidisha district in the North-East. The hill region constitutes about 14 per cent in the Malwa plateau. were selected as a sample of the study with the help of proportionate random sampling method. The Sehore district comprises of 5 blocks namely Sehore, Ashta, Ichhawar, Nasriullaganj and Budhani. Out of these blocks Sehore block was selected due to maximum area covered under vegetable cultivated area. These are 304 villages in Sehore block, out of these 10 villages were selected purposively on the basis of maximum area covered under vegetable cultivation for the study. 12 vegetable growers were selected from each village. Thus, the total 120 vegetable growers were selected as a sample of the study with the help of proportionate random

How to cite this article : Singh, Vikram and Jatav, Hansraj (2020). Knowledge and awareness of farmers with respect to climate change on cropping pattern of vegetable crops in Sehore district of Madhya Pradesh. Agric. Update, 15(4): 411-418; DOI : 10.15740/HAS/AU/15.4/411-418. Copyright@ 2020: Hind Agri-Horticultural Society.
Author for correspondence :

\section{Vikram Singh}

R.A.K. Collage of Agriculture (RVSKVV), Sehore (M.P.) India Email: raj.hans14@gmail. com

See end of the article for authors' affiliations 